\title{
O QUE CONSTITUI UM RESULTADO CIRÚRGICO SATISFATÓRIO? O EXAME RADIOLÓGICO ADEQUADO OU A SATISFAÇÃO DO PACIENTE?
}

relevância em se realizar uma avaliação está subentendida na corre-
ção de atitude advinda do conhecimento de seu resultado. Existem
os métodos de avaliação do sucesso do tratamento médico, indepen-
dentemente do método utilizado existem alguns pré-requisitos básicos a serem respeitados, que são a reprodutibilidade, para permitir uma comparação, a necessidade de haver uma sensibilidade apropriada para o estudo em questão, evitando assim uma conclusão errada, e a maior abrangência possível, para que se tenha uma amostra de todas as variáveis.

A avaliação dos pacientes submetidos à cirurgia de coluna deve abranger, além da avaliação da cirurgia e dos exames radiológicos, a avaliação das questões relativas aos seus problemas pré-cirúrgicos e suas expectativas para com a cirurgia. Esta avaliação global permite que se estabeleça, desde o período pré-operatório, uma medição biopsicossocial do paciente, seu perfil de comportamento, estilo de vida, fatores relacionados ao trabalho, satisfação, insatisfação, medos, crenças, expectativas e qualidade de vida. A teoria da qualidade sugere que, se o resultado do tratamento for igual ou superior à expectativa do paciente, o mesmo estará satisfeito.

Sabe-se que a visão de "resultado satisfatório" sob o ponto de vista do cirurgião não se correlaciona, muitas vezes, com o grau de satisfação obtido pelo paciente. O resultado cirúrgico insatisfatório é uma combinação de inúmeros fatores, o que justifica a necessidade de uma avaliação global do paciente. Assim sendo, os dados obtidos destes questionários permitem medir estes fatores de risco, para que, uma vez conhecidas estas variáveis, haja uma melhor identificação dos pacientes com probabilidade de se beneficiarem com a cirurgia.

Asdrubal Falavigna, MD, PhD

Coordenador do Curso de Medicina

e Professor do Serviço de Neurocirurgia

da Universidade de Caxias do Sul 